\title{
Emergency health care use and follow-up among sociodemographic groups of children who visit emergency departments for mental health crises
}

\author{
Amanda S. Newton PhD, Rhonda J. Rosychuk PhD, Kathryn Dong MSc MD, Janet Curran PhD,
} Mel Slomp MA, Patrick J. McGrath PhD

\begin{abstract}
Background: Previous studies of differences in mental health care associated with children's sociodemographic status have focused on access to community care. We examined differences associated with visits to the emergency department.
\end{abstract}

Methods: We conducted a 6-year populationbased cohort analysis using administrative databases of visits ( $n=30656$ ) by children aged less than 18 years $(n=20956)$ in Alberta. We measured differences in the number of visits by socioeconomic and First Nations status using directly standardized rates. We examined time to return to the emergency department using a Cox regression model, and we evaluated time to follow-up with a physician by physician type using a competing risks model.

Results: First Nations children aged 15-17 years had the highest rate of visits for girls (7047 per 100000 children) and boys (5787 per 100000 children); children in the same age group from families not receiving government subsidy had the lowest rates (girls: 2155 per 100000 children; boys: 1323 per 100000 children). First Nations children (hazard ratio [HR] 1.64; 95\% confidence interval $[\mathrm{Cl}]$ 1.30-2.05), and children from families receiving government subsidies (HR 1.60, $95 \% \mathrm{Cl} 1.30-1.98$ ) had a higher risk of return to an emergency department for mental health care than other children. The longest median time to follow-up with a physician was among First Nations children (79 d; 95\% Cl 60-91 d); this status predicted longer time to a psychiatrist (HR $0.47,95 \% \mathrm{Cl} 0.32-0.70)$. Age, sex, diagnosis and clinical acuity also explained post-crisis use of health care.

Interpretation: More visits to the emergency department for mental health crises were made by First Nations children and children from families receiving a subsidy. Sociodemographics predicted risk of return to the emergency department and follow-up care with a physician.
$\mathrm{E}$ mergency departments are a critical access point for mental health care for children who have been unable to receive care elsewhere or are in crisis. ${ }^{1}$ Care provided in an emergency department can stabilize acute problems and facilitate urgent follow-up for symptom management and family support. ${ }^{1,2}$

Race, ethnic background and socioeconomic status have been linked to a crisis-oriented care patterns among American children. ${ }^{3,4}$ Minority children are less likely than white children to have received mental health treatment before an emergency department visit,, 3 and uninsured children are less likely to receive an urgent mental health evaluation when needed. ${ }^{4}$ Other studies, however, have shown no relation between sociodemographic status and mental health care,, 56 and it may be that different health system characteristics (e.g., pay-for-service, insurance coverage, publicly funded care) interact with sociodemographic status to influence how mental health resources are used. Canadian studies are largely absent in this discussion, despite a known relation between lower income and poorer mental health status, ${ }^{7}$ nationwide documentation of disparities faced by Aboriginal children, ${ }^{8-10}$ and government-commissioned reviews that highlight deficits in universal access to mental health care. ${ }^{11}$

We undertook the current study to examine whether sociodemographic differences exist in the rates of visits to emergency departments for mental health care and in the use of post-crisis health care services for children in Alberta. Knowledge of whether differences exist for children with mental health needs may help identify children who could benefit from earlier intervention to prevent illness destabilization and children who may be disadvantaged in the period after the emergency department visit. We hypothesized
Competing interests: None declared.

This article has been peer reviewed.

Correspondence to: Amanda S. Newton, mandi.newton@ualberta.ca

CMAJ 2012. DOI:10.1503/ cmaj.111697 
that higher rates of emergency department use, lower rates of follow-up physician visits after the initial emergency department visit, and a longer time to physician follow-up would be observed among First Nations children and children from families receiving government social assistance.

\section{Methods}

\section{Patient population and data sources}

We identified a population-based cohort. We included pediatric patients $(<18$ years) who presented to an Alberta emergency department for mental health care between Apr. 1, 2002, and Mar. 31, 2008. To identify the cohort, we used the Ambulatory Care Classification System data- base of Alberta Health and Wellness. ${ }^{12}$ This database is included in Canadian Institute for Health Information re-abstraction studies to ensure data integrity and quality. ${ }^{13}$

This study was approved by the health research ethics board of the University of Alberta, Edmonton, Alberta.

Children included in our cohort had a main ambulatory care diagnosis for mental illness (International Classification of Disease codes F20-F43, F50, F55, F59, F60-F69, F90-F94, F99), mental and behavioural disorders secondary to substance abuse (F10-F19), or intentional self-harm (T71, X60-X69, X70-X84) coded by nosologists and grouped according to diagnostic clusters. ${ }^{14}$ This diagnosis reflects the

Table 1: Pediatric mental health visits to the emergency department by First Nations and socioeconomic status, 2002-2008

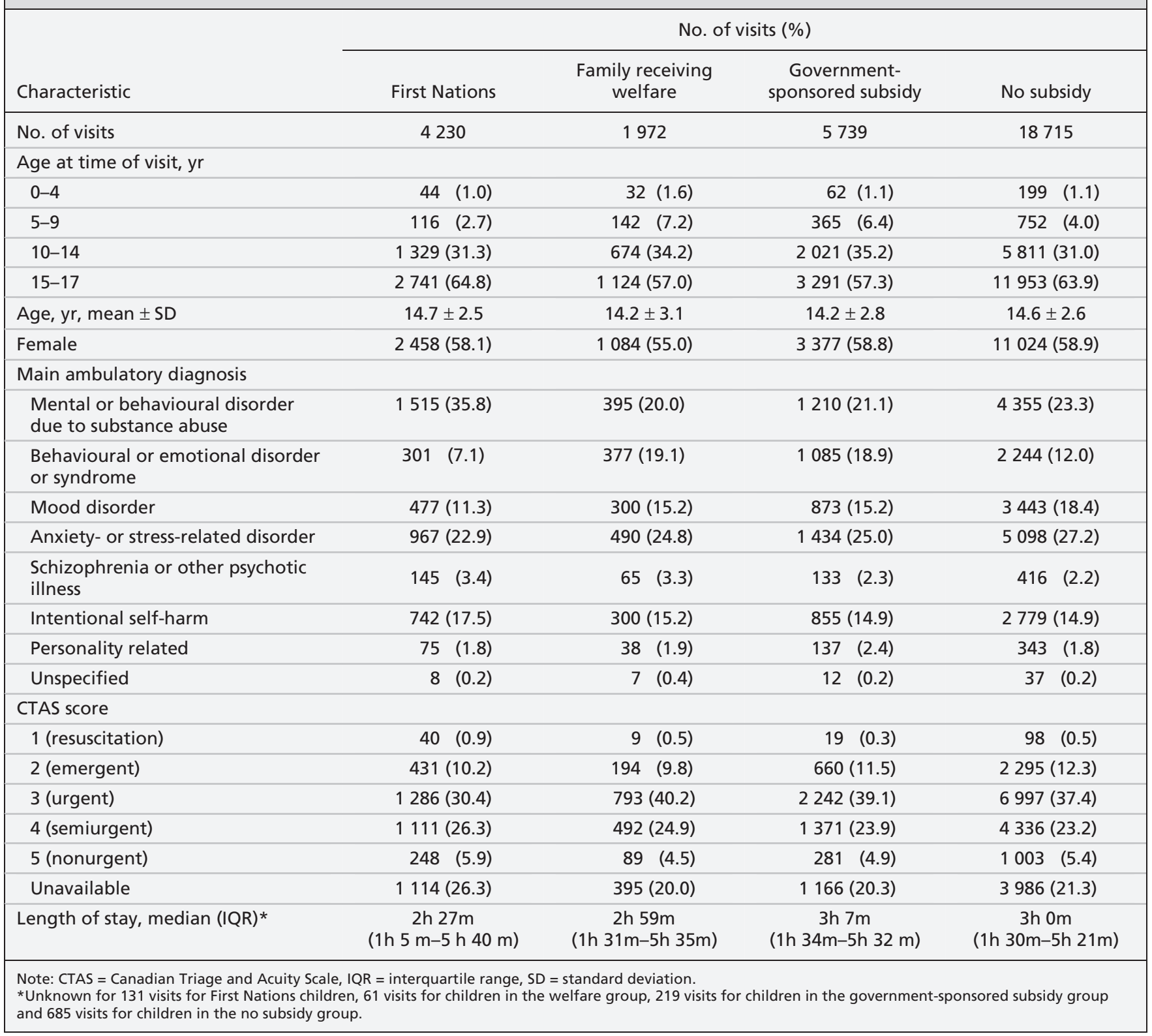


main reason for the provision of emergency services. Recent studies indicate accuracy for a number of diagnoses in the Ambulatory Care Classification System, ${ }^{15,16}$ but these studies do not include mental illnesses.

Data were linked to an annual registry file to obtain sociodemographic data and to a hospitalizations file to obtain start and end dates of hospital stays. Linkage to a physician claim file provided claims for reimbursement to Alberta Health and Wellness (nearly 100\% of physicians) for health care visits following emergency department care (i.e., visits for any care in the post-crisis period). Such claims have been found to have a high concordance with chart reviews and patient interviews. ${ }^{17}$

\section{Sociodemographic main outcomes}

The Ambulatory Care Classification System links to the registry file to identify First Nations Treaty Status people based on treaties between First Nations bands and the Canadian government (children with Treaty Status through registration with Health Canada). Membership in three other groups were also identified in the file, which we categorized as socioeconomic groups under the following headings: regular plan participant (children of families receiving no social assistance), welfare recipient or recipient of other government-sponsored programs because of low income. These three groups reflect the level of government subsidy provided during the study period for provincial health care premiums, which provided revenue for provincial coordination of publicly funded health care in Alberta.

\section{Health care use outcomes}

We defined post-crisis use of health services as return visits to the emergency department for mental health crises and any visit to physicians in the post-crisis period (follow-up visits to hospital and community services). We examined followup physician visits within 180 days of the initial emergency department visit (index visit) and reviewed up to three diagnoses for each visit.

\section{Statistical analysis}

\section{Emergency department visits}

Frequencies and percentages summarize categorical data; continuous data are summarized by mean, standard deviation (SD), median and interquartile range. We calculated age-specific emergency department visits per 100000 Alberta population ( $<18$ years) for each sex. We used the Alberta population in 2002/03 stratified by sex and age group as the reference population for directly standardized visit rates ${ }^{18}$ based on the whole group (with associated 95\% confidence intervals [CIs]). This approach accounts for correlated data arising from multiple visits from one person. We considered $p<0.05$ to be statistically significant.

\section{Post-crisis health services use}

We created a discharged data subset of index emergency department visits with one record per discharged child during the period from Oct. 1, 2006, to Sept. 30, 2007. This subset was created to capture a full year of visits and 180 days of follow-up information. If a child had more than one visit concluding in discharge during this period, we randomly selected one visit to include in the data subset. This construction allowed us to focus on time to follow-up visit after a specific emergency department visit and removed any requirement to adjust for subject-specific correlation in the analyses. We calculated the time from the index visit to the next emergency department visit and first physician follow-up visit; these are displayed with Kaplan-Meier curves and compared with log rank tests.

We developed multivariable Cox proportional hazard models to investigate the effect of predictor variables on time to a return emergency department visit. We included in the models variables hypothesized to predict time to return (age and sex,,$^{19}$ First Nations and socioeconomic status, ${ }^{3,4}$ diagnosis ${ }^{19}$ and triage level [clinical acuity $\left.]^{20}\right)$. We entered variables and interaction terms (age, sex, socioeconomic and First Nations status) into the full model and removed the variables one at a time if they were not statistically significant $(p>0.05)$ to obtain the final model.

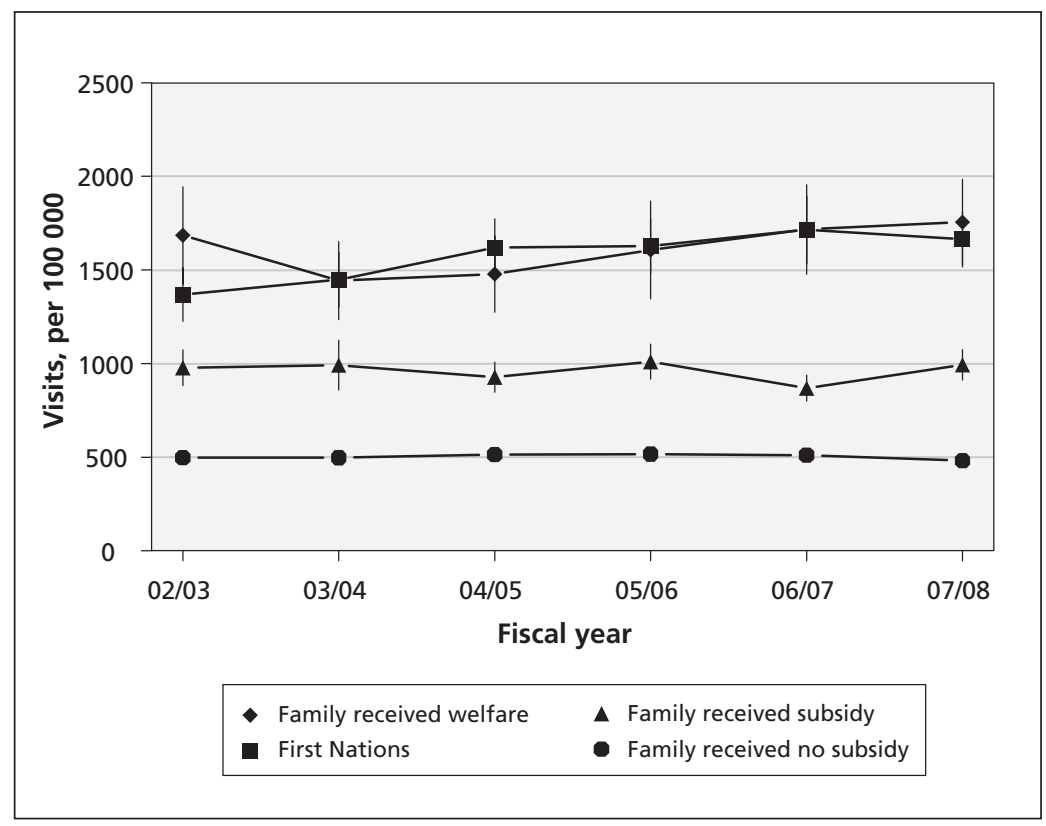

Figure 1: Age- and sex-adjusted directly standardized visit rates (with $95 \%$ confidence interval) for each fiscal year by First Nations and socioeconomic status. 
We assessed the reduced model by tests of proportional hazards assumptions and deviance residual diagnostics. Hazard ratios (HR) and 95\% CIs are reported.

For the analyses of follow-up visits to physicians, time was censored at the end of the study or the date of the next emergency department visit. We report the estimated median times (with 95\% CIs), and we compared the groups using log-rank tests. Multivariable regression with competing risks modelled time to first physician follow-up visit by physician type. This analysis included only mental health-related follow-up visits or censored data. As with the Cox model, the same interaction terms, model building strategy and variables were used to obtain a final model, and HRs and 95\% CIs are reported.

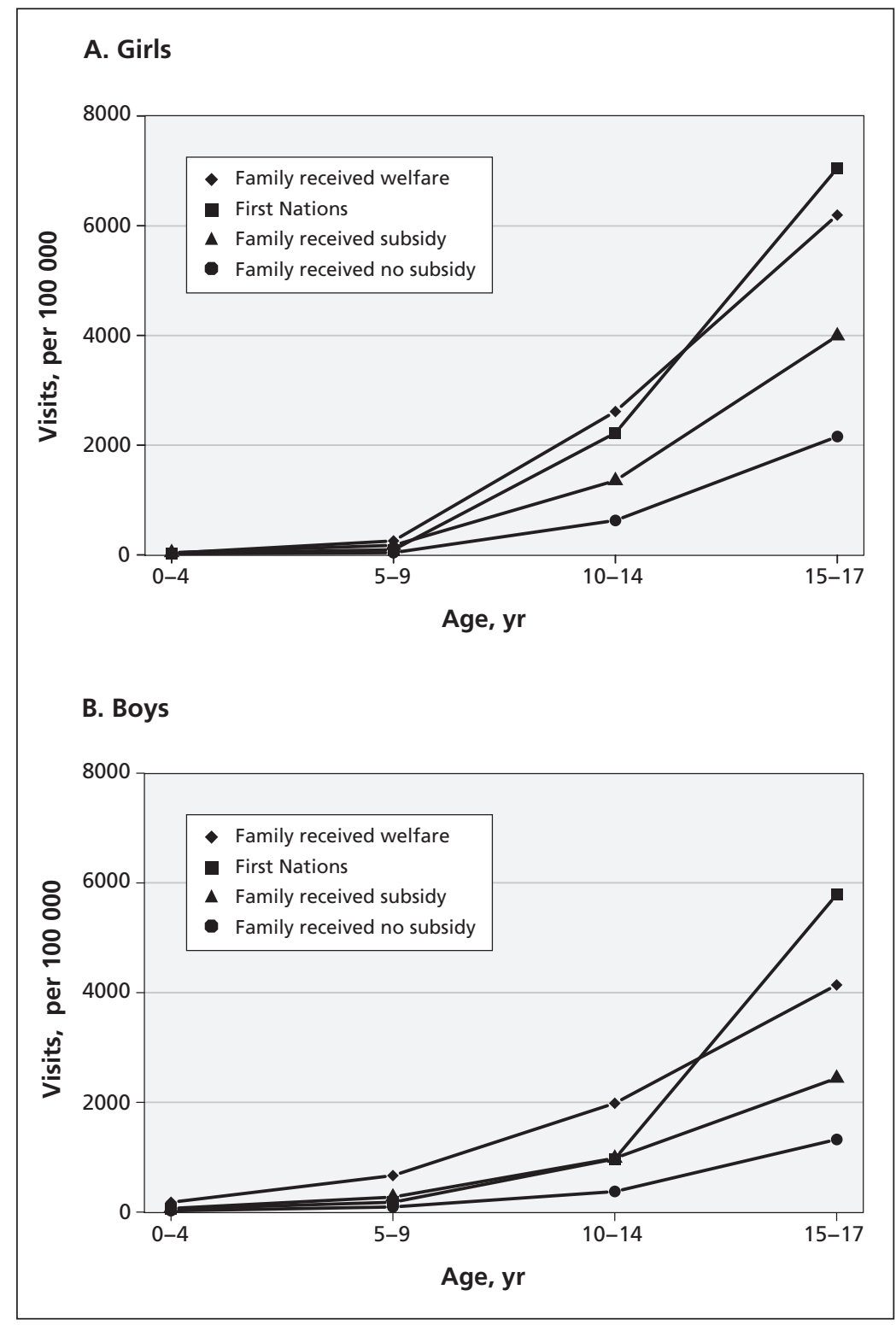

Figure 2: Age- and sex-specific emergency department visit rates by First Nations and socioeconomic status, 2007/08.
In the final adjusted Cox and competing risks models, HRs greater than 1.0 represent an increased risk of early use of post-crisis health care, and HRs less than 1.0 represent a decreased risk of early use based on a particular characteristic (sociodemographic status) or level of acuity or diagnosis during the index emergency department visit.

\section{Results}

\section{Emergency department visits}

During the 6-year period, 30656 mental health visits were made by 20956 children to 104 emergency departments in Alberta. Visit characteristics are provided in Table 1. Of all visits, $61.0 \%$ were made by children from families who received no form of government subsidy for health care. On average from 2002 to 2008, First Nations children represented $6.0 \%$ of the Alberta pediatric population, children from families receiving welfare represented $3.0 \%$, and children from families receiving subsidy from government-sponsored programs represented $14 \%$. Children in these groups had disproportionately more emergency department visits: $13.8 \%$ (4230/30 656 visits) among First Nations children, 6.4\% (1972/30 656 visits) among children from families receiving welfare, and 18.7\% (5739/30 656 visits) among children from families receiving subsidy from government-sponsored programs. Across the sociodemographic groups, more visits were made by girls and youth aged 15-17 years. Nearly the same proportions were observed during each fiscal year. The most common diagnoses in each sociodemographic group were anxiety-or stress-related disorder and mental or behavioural disorders resulting from substance abuse.

Standardized visit rates declined for children from families without subsidy and increased for all other children (Figure 1, Appendix 1, available at www.cmaj.ca/lookup/suppl/doi:10.1503/cmaj $.111697 /-/ D C 1)$. First Nations children had the largest visit rate increase from 2002/03 to 2007/08 (1368.0/100 000 children to 1664.0/100 000 children; $p=0.004)$. The directly standardized visit rates for children from families receiving welfare were among the highest across all years, but there was no evidence of a statistically significant change over time $(p=0.7)$. Age- and sex-specific visit rates differed by sociodemographic group in 2007/08 (Figure 2). First Nations children and children from families receiving welfare had higher rates, most noticeably for girls aged $15-17$ years (7047.6 and 6194.2/100 000 children) and boys (5787.3 and 4140.3/100 000 children). 


\section{Post-crisis use of health care services}

Between Oct. 1, 2006, and Sept. 30, 2007, a total of 3438 children were discharged from the emergency department, forming our discharged subset. Of these children, 509 (14.8\%) were First Nations, 654 (19.0\%) were from families receiving subsidy from government-sponsored programs, $233(6.8 \%)$ were from families receiving welfare, and 2042 (59.4\%) were from families without subsidy. Trends in return visits to the emergency department by sociodemographic group were more pronounced by 30 days after discharge (Figure 3, Table 2). First Nations children and those from families receiving subsidy from government-sponsored programs returned earlier to the emergency department than other children $(p<0.001)$. As shown in Table 3 , these children had a higher risk of returning sooner. The risk of return also increased with age and receipt of an unspecified diagnosis during the first visit. Boys were less likely to return to the emergency department after crises than girls. Interactions between age, sex and sociodemographic status and these main effects were not statistically significant.

Seven days after an index emergency department visit, $76.9 \%$ (2644/3438) of children did not follow up with a physician (Table 2). Among children who had a follow-up visit, most visits were for mental health concerns $(70.2 \%)$, made to psychiatrists $(53.2 \%)$ and conducted in active treatment hospitals $(57.1 \%)$. Differences in follow-up visits were observed among sociodemographic groups $(p<0.001)$. First Nations children had fewer follow-up visits after discharge from the emergency department. The median time to physician follow-up for First Nations children was 79 d (95\% CI 60-91 d), a time substantially longer than the group with the shortest time (29 d, 95\% CI 22-41 d; Figure 3).

Predictors of time to a follow-up physician visit for mental health care differed by type of physician (Table 4). Compared with other children, First Nations children were more likely to have a longer time to follow-up with a psychiatrist, while children from families receiving governmentsponsored subsidies were more likely to have a longer time to follow-up with a general practitioner. Age, sex, diagnosis and clinical acuity also explained time to follow-up physician visits (Table 4).

\section{Interpretation}

We found significant variation across sociodemographic groups of children in crisis and post-crisis health care use over a 6-year period in Alberta. The largest increase in visits to the emergency depart- ment for mental health crises was among First Nations children. First Nations children and those from families receiving subsidy from governmentsponsored programs had more return visits to emergency departments over time compared with other children. First Nations children also had disproportionately less follow-up care with a physician after an emergency department visit and had longer times to follow-up care. Sociodemographic status, diagnosis and illness acuity were significant predictors of time to post-crisis health care use.

Multiple studies have shown that race and ethnic background influence access to mental health services and emergency care for children. ${ }^{3,4}$ To the best of our knowledge, our group is the first to report on the use of emergency mental health care among First Nations children.

\section{A. Return ED visits}

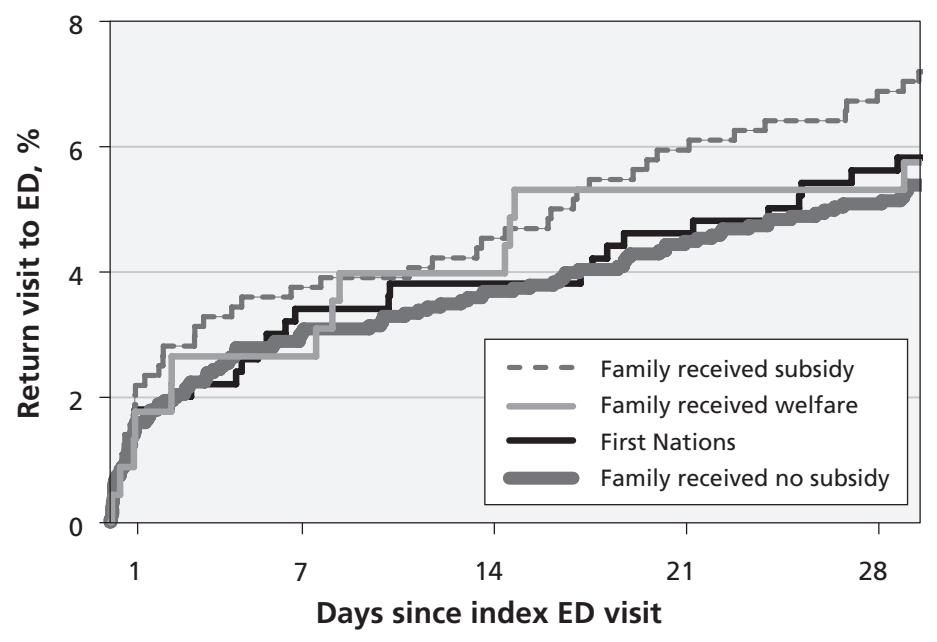

\section{B. Follow-up physician visit}

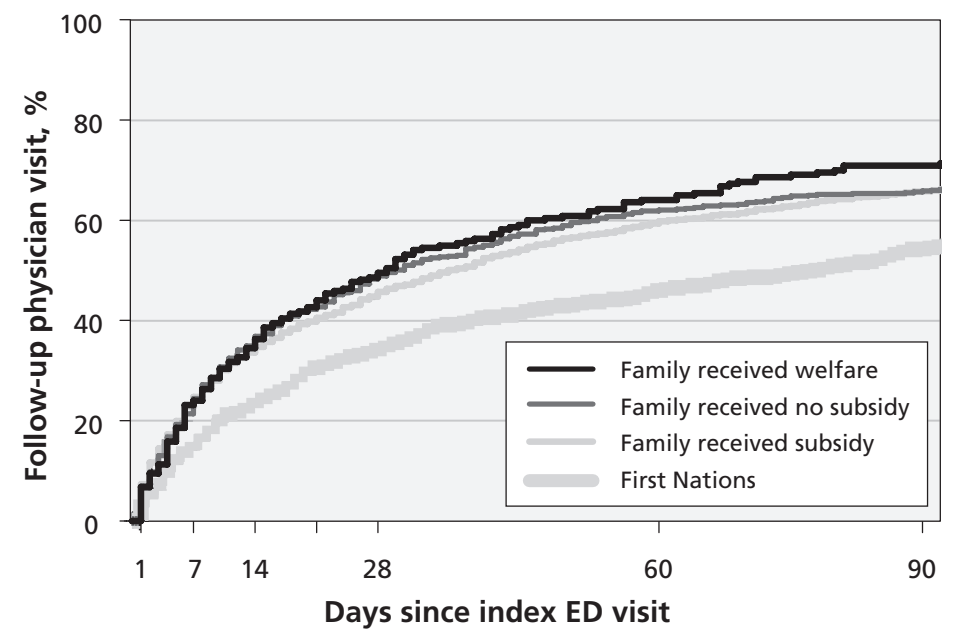

Figure 3: Time to return visit to the emergency department (ED) (A) and time to follow-up visit (B) after discharge, by First Nations and socioeconomic status. 
We currently have a poor understanding of the prevalence of mental illness among these children. In the 2002/03 First Nations Regional Longitudinal Health Survey, 17\% of First Nations parents reported a modest percentage of behavioural and emotional problems among their children. ${ }^{21}$ Other studies suggest more substance use, ${ }^{8}$ more symptoms of conduct disorder ${ }^{9}$ and higher completed suicide rates among First Nations children than among other children. ${ }^{10} \mathrm{We}$ found that more First Nations children presented to emergency departments for disorders sec- ondary to substance abuse and intentional selfharm than other children, and that, compared with other children, First Nations children returned more quickly to the emergency department and had a longer time before visiting a physician in the post-crisis period. These findings suggest that investments in culturally based, community- and school-based resources targeting the high-risk behaviours seen in the emergency department may help to reduce crisis events and foster the use of mental health resources. ${ }^{22}$ Although such resources would not

Table 2: Follow-up visits among discharged children $(n=3$ 438) from Oct. 1, 2006, to Sept. 30, 2007

\begin{tabular}{|c|c|c|c|c|}
\hline \multirow[b]{2}{*}{ Variable } & \multicolumn{4}{|c|}{ Days since index emergency department visit; no. (\%)* } \\
\hline & 7 & 14 & 30 & 90 \\
\hline Follow-up visits, no. & 2094 & 3643 & 6868 & 16761 \\
\hline \multicolumn{5}{|l|}{ Age at index visit, yr } \\
\hline $0-4$ & $14(0.7)$ & $26(0.7)$ & $44(0.6)$ & $103 \quad(0.6)$ \\
\hline $5-9$ & $121(5.8)$ & $220(6.0)$ & $368(5.4)$ & $946 \quad(5.6)$ \\
\hline $10-14$ & $583(27.8)$ & $995(27.3)$ & $2034(29.6)$ & $5053(30.1)$ \\
\hline 15-17 & $1376(65.7)$ & $2402(65.9)$ & $4422(64.4)$ & 10659 (63.6) \\
\hline Female & $1290(61.6)$ & $2299(63.1)$ & $4346(63.3)$ & $10255(61.2)$ \\
\hline \multicolumn{5}{|l|}{ First Nations or socioeconomic status } \\
\hline First Nations & $161(7.7)$ & $298 \quad(8.2)$ & $597(8.7)$ & $1643 \quad(9.8)$ \\
\hline Family received welfare & $139(6.6)$ & $274 \quad(7.5)$ & $551(8.0)$ & $1331 \quad(7.9)$ \\
\hline Family received government-sponsored subsidy & $428(20.4)$ & $764(21.0)$ & $1393(20.3)$ & $3551(21.2)$ \\
\hline Family received no subsidy & $1366(65.2)$ & $2307(63.3)$ & $4327(63.0)$ & $10236(61.1)$ \\
\hline \multicolumn{5}{|l|}{ Main ambulatory diagnosis } \\
\hline $\begin{array}{l}\text { Mental or behavioural disorder due to substance } \\
\text { abuse }\end{array}$ & $260(12.4)$ & $441(12.1)$ & $845(12.3)$ & $2377(14.2)$ \\
\hline Behavioural or emotional disorder or syndrome & $52(2.5)$ & $118 \quad(3.2)$ & $224(3.3)$ & $536 \quad(3.2)$ \\
\hline Mood disorder & $529(25.3)$ & $894(24.5)$ & $1625(23.7)$ & $3681(22.0)$ \\
\hline Anxiety- or stress-related disorder & $526(25.1)$ & 969 (26.6) & $1899(27.6)$ & $4372(26.1)$ \\
\hline Schizophrenia or other psychotic illness & $0 \quad(0)$ & $0 \quad(0)$ & $202(2.9)$ & $495 \quad(3.0)$ \\
\hline Intentional self-harm & 326 (15.6) & $533(14.6)$ & $925(13.5)$ & $2520(15.0)$ \\
\hline Personality related & $54(2.6)$ & $66(1.8)$ & $113(1.6)$ & $253 \quad(1.5)$ \\
\hline Unspecified & $0 \quad(0)$ & $0 \quad(0)$ & $25(0.4)$ & $38 \quad(0.2)$ \\
\hline \multicolumn{5}{|l|}{ Physician seen during follow-up visit } \\
\hline General practitioner & $707(33.8)$ & $1234(33.9)$ & $2328(33.9)$ & $5472(32.6)$ \\
\hline Pediatrician & $94(4.5)$ & $188(5.2)$ & $348(5.1)$ & $838 \quad(5.0)$ \\
\hline Psychiatrist & $1113(53.2)$ & $1920(52.7)$ & 3669 (53.4) & $9050(54.0)$ \\
\hline Other & $180(8.6)$ & $301 \quad(8.3)$ & $523(7.6)$ & 1401 \\
\hline \multicolumn{5}{|l|}{ Facility type for follow-up visit } \\
\hline Active treatment hospital & $1196(57.1)$ & $2017(55.4)$ & $3885(56.6)$ & $9242(55.1)$ \\
\hline Mental health service & $63(3.0)$ & $108(3.0)$ & $228(3.3)$ & $681 \quad(4.1)$ \\
\hline Practitioner's office & $808(38.6)$ & $1458(40.0)$ & $2616(38.1)$ & $6444(38.4)$ \\
\hline Other & $27 \quad(1.3)$ & $60 \quad(1.6)$ & $139(2.0)$ & $394 \quad(2.4)$ \\
\hline \multicolumn{5}{|l|}{ Follow-up visit diagnosis } \\
\hline Mental health based & $1471(70.2)$ & $2464(67.6)$ & $4573(66.6)$ & 10822 (64.6) \\
\hline
\end{tabular}


have been captured through physician billing in our study, the high rates of emergency department use suggest that if such services do exist and are being used, they may not be specific or comprehensive enough to reduce crises.

Our findings also reflect access and utilization issues. In the 2002/03 Regional Longitudinal Health Survey, parents reported long waits for health care (91.4\% of respondents) and lack of service coverage by the First Nations and Inuit Health Branch (10.6\% of respondents) as significant barriers to health care access. ${ }^{21}$ To what extent these barriers limit access to and the use of mental health services is not known. In our study, First Nations children had the longest times to physician follow-up care, but First Nations status alone did not predict time to most follow-up visits. To reduce mental health crises and tailor care, more investigation is needed to better understand the relation between crisis-oriented patterns of care, delays in receiving follow-up care, and the services desired and sought in a post-crisis period by First Nations children and their families.

Consistent with our hypotheses, children from families receiving subsidy (welfare and other government-sponsored programs) also had some of the highest rates of emergency department visits and revisits, with government-sponsored subsidy status predicting a quicker return. Contrary to one of our hypotheses, however, these children, in general, did not have longer times to fol- low-up than other children for a follow-up physician visit. Our findings of increased use of health services among a lower socioeconomic group of children are similar to other Canadian studies examining the use of community-based mental health services ${ }^{23}$ but dissimilar to research on return visits to the emergency department. ${ }^{19}$ Whether high rates of visits by children in our study reflect a lack of access to pre-crisis care, delays in seeking care until crises emerge or other factors (e.g., geography) could not be answered with the Ambulatory Care Classification System, but these factors are important to determine. A lack of access has implications for the availability of services in neighbourhoods that differ by socioeconomic status. Delays in mental health care for children have been linked to time lags between generalist care and specialist referrals ${ }^{24}$ and service proximity. ${ }^{25}$

\section{Limitations}

Our study has several limitations. First, we were limited by diagnostic reporting. Although recent studies using Ambulatory Care Classification System data indicate diagnostic accuracy, ${ }^{15,16}$ no formal assessment of mental health diagnostic coding in ambulatory care has been conducted.

Second, the databases used do not identify all Aboriginal children; non-Treaty Status, Inuit and Métis children were not included.

Third, we could not determine the influence

Table 3: Predictors of time to a return visit to the emergency department for mental health care among 3438 children

\begin{tabular}{|lcc|}
\hline Variable & Hazard ratio $(95 \% \mathrm{Cl})^{*}$ & $p$ \\
\hline Age group at index visit, yr & & \\
\hline $0-4$ & Reference & 0.04 \\
\hline $5-9$ & $7.95(1.10-57.69)$ & 0.02 \\
\hline $10-14$ & $10.10(1.44-70.79)$ & 0.01 \\
\hline $15-17$ & $12.37(1.77-86.52)$ & \\
\hline Sex & & $<0.001$ \\
\hline Female & Reference & \\
\hline Male & $0.72(0.61-0.86)$ & $<0.001$ \\
\hline First Nations or socioeconomic status & & $<0.001$ \\
\hline Family received no subsidy or welfare & $1.65(1.32-2.06)$ & \\
\hline First Nations & $1.63(1.34-1.99)$ & $<0.001$ \\
\hline $\begin{array}{l}\text { Family received government-sponsored } \\
\text { subsidy }\end{array}$ & & 0.03 \\
\hline Main ambulatory diagnosis at index visit & Reference & \\
\hline All other diagnoses & $0.58(0.48-0.70)$ & \\
\hline Anxiety- or stress-related disorder & $2.97(1.11-7.97)$ & \\
\hline Unspecified & & \\
\hline $\begin{array}{l}\text { Note: Cl = confidence interval. } \\
\text { *Multivariable Cox regression. }\end{array}$ & & \\
\hline
\end{tabular}


Table 4: Predictors of time to physician follow-up visit for mental health care among 1857 children

\begin{tabular}{|c|c|c|}
\hline & Hazard ratio $(95 \% \mathrm{Cl})^{*}$ & $p$ \\
\hline \multicolumn{3}{|l|}{ Follow-up with psychiatrist } \\
\hline \multicolumn{3}{|l|}{ Age at index visit } \\
\hline $10-14 \mathrm{yr}$ & $1.26(1.04-1.53)$ & 0.02 \\
\hline All other age groups & Reference & \\
\hline \multicolumn{3}{|l|}{ First Nations or socioeconomic status } \\
\hline First Nations & $0.47(0.32-0.70)$ & $<0.001$ \\
\hline All other sociodemographic groups & Reference & \\
\hline \multicolumn{3}{|l|}{ Main ambulatory diagnosis at index visit } \\
\hline $\begin{array}{l}\text { Mental or behavioural disorder due to } \\
\text { substance abuse }\end{array}$ & $0.21(0.15-0.29)$ & $<0.001$ \\
\hline Anxiety- or stress-related disorder & $0.50(0.40-0.63)$ & $<0.001$ \\
\hline Schizophrenia or other psychotic Illness & $2.78(1.77-4.36)$ & $<0.001$ \\
\hline All other diagnoses & Reference & \\
\hline \multicolumn{3}{|l|}{ CTAS score } \\
\hline All other CTAS scores & Reference & \\
\hline 4 (semiurgent) & $0.70(0.55-0.89)$ & 0.003 \\
\hline 5 (nonurgent) & $0.53(0.34-0.82)$ & 0.005 \\
\hline 9 (unavailable) & $0.65(0.44-0.96)$ & 0.03 \\
\hline \multicolumn{3}{|l|}{ Follow-up with a general practitioner } \\
\hline \multicolumn{3}{|l|}{ Age at index visit } \\
\hline $10-14 \mathrm{yr}$ & $0.76(0.60-0.94)$ & 0.01 \\
\hline All other age groups & Reference & \\
\hline \multicolumn{3}{|l|}{ Sex } \\
\hline Female & Reference & \\
\hline Male & $0.72(0.58-0.88)$ & 0.002 \\
\hline \multicolumn{3}{|l|}{ First Nations or socioeconomic status } \\
\hline Family received a government-sponsored subsidy & $0.67(0.50-0.89)$ & 0.006 \\
\hline All other sociodemographic groups & Reference & \\
\hline \multicolumn{3}{|l|}{ Main ambulatory diagnosis at index visit } \\
\hline Mental or behavioural disorder due to substance abuse & $0.43(0.32-0.56)$ & $<0.001$ \\
\hline Behavioural or emotional disorder or syndrome & $0.70(0.51-0.94)$ & 0.02 \\
\hline Intentional self-harm & $0.56(0.38-0.81)$ & 0.002 \\
\hline All other diagnoses & Reference & \\
\hline \multicolumn{3}{|l|}{ Follow-up with a pediatrician } \\
\hline \multicolumn{3}{|l|}{ Age at index visit } \\
\hline $0-4 \mathrm{yr}$ & $3.30(1.26-8.63)$ & 0.02 \\
\hline $5-9 \mathrm{yr}$ & $2.25(1.12-4.52)$ & 0.02 \\
\hline All other age groups & Reference & \\
\hline \multicolumn{3}{|l|}{ Main ambulatory diagnosis at index visit } \\
\hline Behavioural or emotional disorder or syndrome & $3.58(2.01-6.37)$ & $<0.001$ \\
\hline Unspecified & $8.01(1.13-56.71)$ & 0.04 \\
\hline All other diagnoses & Reference & \\
\hline \multicolumn{3}{|l|}{ Follow-up with other physician type } \\
\hline \multicolumn{3}{|l|}{ Age at index visit } \\
\hline $10-14 \mathrm{yr}$ & $0.38(0.17-0.86)$ & 0.02 \\
\hline All other age groups & Reference & \\
\hline \multicolumn{3}{|l|}{ Main ambulatory diagnosis at index visit } \\
\hline Personality related & $6.01(1.85-19.56)$ & 0.003 \\
\hline All other diagnoses & Reference & \\
\hline
\end{tabular}


of either pre-crisis mental health care, contact with non-physician resources in the post-crisis period or other variables hypothesized to influence the use of health care. Higher rates of visits to emergency departments may be the result of a disproportionately high use of emergency services over other medical services or a preference for emergency care. Longer times to physician follow-up in our study may reflect access to other mental health services in the child's community (private clinics, community-based programs designed for specific sociodemographic groups). Child- or family-specific determinants (e.g., stress, stigma, family constellation and psychiatric history) likely further explain both crisis and post-crisis health care use, but these were not available in the Ambulatory Care Classification System. Although this database limitation is not unique to our study, it does point to important considerations for administrative datacapture parameters and how to increase the contributions of these repositories for health care decision-making.

Finally, although others have reported the same socioeconomic proxy definition, ${ }^{26}$ our use of health care premium subsidy may not have always accurately reflected a child's socioeconomic status.

\section{Conclusion}

Visits to the emergency department for mental health care should be considered a "stop gap" solution in the full suite of mental health services. For many children, these visits reflect a need for earlier intervention to prevent illness destabilization into crisis. Further, children with longer times to follow-up care in the post-crisis period may also be disadvantaged because they likely require continued support for stabilization. We found that sociodemographic status plays an important role in the post-crisis use of health care services.

A recent US-based study reported continued use of emergency departments for pediatric mental health care despite linkage to communitybased services, ${ }^{27}$ which suggests that seeking health care is not solely patterned by features of the health care system. Factors such as stigma and discrimination ${ }^{28}$ single-parenthood ${ }^{29}$ and parent unemployment ${ }^{29}$ are linked with service use and should be a priority for understanding predictors of the time to and use of mental health care. Such a line of investigation may help to explain the varied patterns of emergency department use and follow-up physician care observed among the different sociodemographic groups in our study.

Although recent treatment in an emergency department has been shown to be a strong predictor of follow-up mental health care for suiciderelated behaviours ${ }^{30}$ our study also suggests that the time to post-crisis care is affected by age, sex, diagnosis and clinical acuity. Future studies that determine why the risk for repeat crisis events increases with age are worthwhile and could query, for example, whether youth are particularly vulnerable because of their developmental struggles for autonomy. Moving ahead, our findings that when a child leaves the emergency department with an unspecified diagnosis they are more likely to return sooner in crisis or that certain diagnoses (substance abuse, anxiety) and less urgent presentations (e.g., lower triage scores) involve longer times to follow-up care could inform current discharge planning processes in Canada's emergency departments without fiscal or human resource impact.

\section{References}

1. Dolan MA, Mace SE; American Academy of Pediatrics, Committee on Pediatric Emergency Medicine, American College of Emergency Physicians and Pediatric Emergency Medicine Committee. Pediatric mental health emergencies in the emergency medical services system. Pediatrics 2006;118:1764-7.

2. Dolan MA, Fein JA; Committee on Pediatric Emergency Medicine. Technical report: pediatric and adolescent mental health emergencies in the emergency medical services system. Pediatrics 2011;127:e1356-66.

3. Snowden LR, Masland MC, Libby AM, et al. Racial/ethnic minority children's use of psychiatric emergency care in California's public mental health system. Am J Public Health 2008;98:118-24.

4. Kataoka SH, Zhang L, Wells KB. Unmet need for mental health care among US children: variation by ethnicity and insurance status. Am J Psychiatry 2002;159:1548-55.

5. Sturm R, Ringel JS, Andreyeva T. Geographic disparities in children's mental health care. Pediatrics 2003;112:e308.

6. Zahner GEP, Pawelkiewicz W, DeFrancesco JJ, et al. Children's mental health service needs and utilization patterns in an urban community: an epidemiological assessment. J Am Acad Child Adolesc Psychiatry 1992;31:951-60.

7. Lipman EL, Offord DR, Boyle MH. Relation between economic disadvantage and psychosocial morbidity in children. CMAJ 1994;151:431-7.

8. Gfellner BM, Hundleby JD. Patterns of drug use among Native and white adolescents: 1990-1993. Can J Public Health 1995;86:95-7.

9. Sack WH, Beiser M, Phillips N, et al. Co-morbid symptoms of depression and conduct disorder in First Nations children: some findings from the Flower of Two Soils Project. Cult Med Psychiatry 1992-1993;16:471-86

10. Edwards N, Alaghehbandan R, MacDonald D, et al. Suicide in Newfoundland and Labrador: a linkage study using medical examiner and vital statistics data. Can J Psychiatry 2008;53:252-9.

11. Kirby MJL, Keon WJ. Mental health, mental illness and addiction: overview of policies and programs in Canada. Ottawa (ON): The Standing Senate Committee on Social Affairs, Science and Technology; 2004. Available: www.parl.gc.ca/Content /SEN/Committee/381/soci/rep/repintnov04-e.htm (accessed 2012 Jan. 16).

12. Ambulatory care in Alberta using Ambulatory Care Classification System data. Edmonton (AB): Alberta Health and Wellness; 2004.

13. Alberta Health and Wellness Ambulatory Care Re-abstraction Study executive report. Edmonton (AB): Alberta Health and Wellness; 2006.

14. World Health Organization. International statistical classification of diseases and related health problems. 10th rev. Geneva (Switzerland): The Organization; Available: www.who.int/classifications /icd/en (accessed 2001 May 6).

15. Kelly KD, Rowe BH, Lissel H, et al. Sports and recreation head injury treated in the emergency department. Clin J Sport Med 2001; $11: 77-81$.

16. Colman I, Dryden DM, Thompson AH, et al. Utilization of the emergency department after self-inflicted injury. Acad Emerg Med 2004;11:136-42.

17. Roos LL, Nicol JP, Cageorge SM. Using administrative data for longitudinal research: comparisons with primary data collection. J Chronic Dis 1987;40:41-9. 
18. Carriere KC, Roos LL. Comparing standardized rates of events. Am J Epidemiol 1994; 140:472-82.

19. Newton AS, Ali S, Johnson DW, et al. Who comes back? Characteristics and predictors of return to emergency department services for pediatric mental health care. Acad Emerg Med 2010;17:177-86.

20. Yu AY, Rosychuk RJ, Newton AS. Clinical acuity of repeat pediatric mental health presentations to the emergency department. $J$ Can Acad Child Adolesc Psychiatry 2011;20:208-13.

21. Aboriginal Centre. Aboriginal Regional Longitudinal Health Survey (RHS) 2002/03. Results for adults, youth and children living in aboriginal communities. Ottawa (ON): The Centre; 2005.

22. Harrison ME, McKay MM, Bannon WM. Inner-city child mental health service use: the real question is why youth and families do not use services. Community Ment Health J 2004;40:119-31.

23. Offord DR, Boyle MH, Szatmari P, et al. Ontario child health study: six-month prevalence of disorder and rates of service utilization. Arch Gen Psychiatry 1987;44:832-6.

24. Steel Z, McDonald R, Silove D, et al. Pathways to the first contact with specialist mental health care. Aust N Z J Psychiatry 2006; 40:347-54.

25. Boyd CP, Hayes L, Nurse S, et al. Preferences and intention of rural adolescents toward seeking help for mental health problems. Rural Remote Health 2011;11:1582.

26. Rowe BH, Voaklander DC, Wang D, et al. Asthma presentations by adults to emergency departments in Alberta, Canada. A large population-based study. Chest 2009;135:57-65.

27. Frosch E, dosReis S, Maloney K. Connections to outpatient mental health care of youths with repeat emergency department visits for psychiatric crises. Psychiatr Serv 2011;62:646-9.

28. Thornicroft G. Stigma and discrimination limit access to mental health care. Epidemiol Psichiatr Soc 2008;17:14-9.

29. Gunther N, Slavenburg B, Feron F, et al. Childhood social and early developmental factors associated with mental health service use. Soc Psychiatry Psychiatr Epidemiol 2003;38:101-8.

30. Bridge JA, Marcus SC, Olfson M. Outpatient care of young people after emergency treatment of deliberate self-harm. $J A m$ Acad Child Adolesc Psychiatry 2012;51:213-222.e1.

Affiliations: From the Department of Pediatrics (Newton, Rosychuk); the Department of Psychiatry (Newton); the Department of Emergency Medicine (Dong), Faculty of
Medicine \& Dentistry, University of Alberta, Edmonton, Alta.; Women and Children's Health Research Institute (Rosychuk), Edmonton, Alta; Clinical Epidemiology Program (Curran), Ottawa Hospital Research Institute, Ottawa, Ont.; Knowledge \& Strategy (Slomp), Alberta Health Services, Edmonton, Alta.; IWK Health Centre (McGrath), Halifax, NS; and the Departments of Pediatrics and Psychology (McGrath), Dalhousie University, Halifax, NS.

Contributors: Rhonda Rosychuk and Amanda Newton had full access to all of the data in the study and take responsibility for the integrity of the data and the accuracy of the data analysis. Amanda Newton conceived and designed the study. Rhonda Rosychuk acquired data. All of the authors analyzed and interpreted the data, drafted the manuscript and critically revised it for important intellectual content. Rhonda Rosychuk performed the statistical analysis. Rhonda Rosychuk and Amanda Newton obtained funding. Amanda Newton and Rhonda Rosychuk supervised the study. All of the authors approved the final version submitted for publication.

Funding: Funding for this project was provided by a Catalyst grant awarded to Rhonda Rosychuk and Amanda Newton from the Canadian Institutes of Health Research (CIHR; 200809MCH, FRN\#97596). Amanda Newton holds a CIHR New Investigator Award. Rhonda Rosychuk is a Health Scholar with Alberta Innovates-Health Solutions. Patrick McGrath holds a Canada Research Chair (Tier 1) in pediatric pain. The sponsor had no role in the specific conduct of the review; in the collection, management, analysis, and interpretation of the data; or in the preparation, review or approval of the manuscript.

Acknowledgements: This study is based in part on data provided by Alberta Health and Wellness. The interpretation and conclusions contained herein are those of the researchers and do not necessarily represent the views of the Government of Alberta. Neither the Government of Alberta nor Alberta Health and Wellness express any opinion in relation to this study. 